\title{
Studying the Effect of Planned Behavior Theory and Perceived Value through the Tendency to Purchase on Customers Purchase Behavior towards Green Products
}

\author{
Seyyed Amir Hesam Fazeli ${ }^{1}$, Masoud Simkhah ${ }^{2}$, Kiumars Kiyani $^{3}$ \\ ${ }^{1}$ Graduate Student of Executive Master of Business Administration (EMBA) group, Islamic \\ Azad University of Parand, Parand, Iran. \\ ${ }^{2}$ Management group, Paran Unit, Islamic Azad University of Parand, Parand, Iran. \\ simkhahmasoud@gmail.com \\ ${ }^{3}$ Management group, Paran Unit, Islamic Azad University of Parand, Parand, Iran.
}

\author{
ARTICLE INFO \\ Keywords: \\ planned behavior, \\ perceived value, \\ willingness to \\ purchase, and \\ Customers \\ purchase behavior
}

\begin{abstract}
In this research, we studied the effect of planned behavior theory and perceived value through the willingness to purchase on customers purchase behavior towards green products. This is an applied research in terms of its goal and considered as descriptiveco relational-survey research. The statistical population of this research is all customers of big hypermarkets (hyperme and hyperstar) in Tehran who have green products in their shopping baskets. Due to the unlimited population of the statistical population, the sample size was 384 by using unlimited Cochran formula. Information in this research is collected through library and field methods. In this study, content validity method was used to assess the validity of the questionnaire. To assess the reliability, Cronbach's alpha coefficient was estimated at 0 /95.4. To analyze the data, descriptive tests such as percentage, mean and standard deviation and inferential tests such as Pearson correlation, confirmatory factor analysis and structural equations with LISREL Software were used. Based on the results of the present study, each of the nine examined hypotheses including behavioral beliefs, normative beliefs, control beliefs, attitudes, mental norms, perceived value behavioral control, willingness to pay surplus, and the willingness to purchase green products have been confirmed and significantly affected on customers purchase behavior.
\end{abstract}

\section{Introduction}

Today, ethics and environmental principles have become an important issue among organizations as well as consumers, and uninterrupted deterioration of an environment has been raised. (Moisander, 2007). The issue of environment protection, which in turn leads to normative consumption, is known as a green consumerism. Ethical and normative consumption has been more attracted by academics as well as specialists (Papaoikonomou, 2011). It can be said that in the last few years, the process of focusing on the environment has been increased and the environment has been raised as an important phenomenon all over the world (Gian and Kaur, 2010). 
Increasing the focus on environmental protection and environmental norms has also changed the purchasing performance of consumers. Over time, consumers have begun to show normative behavior through consuming green products, which is considered as one of the extensive categories of ethical and normative consumption (Kim, H.Y., Chung ${ }^{3}$, 2011). Green consumerism grew rapidly in developing countries, but over time, this concept established as a norm in developing countries, including Iran. When green products are popular in the markets, more consumers are moving towards greener products (Chung, 2012). Therefore, understanding the customer's view in direction of willingness to purchase green products is very important for marketers since it helps them formulate appropriate strategies for the development of green products markets (Nimse et al. 2007). Mohammadian et al. (2011) argue that manufacturing companies, society (consumers), and governments have three sides of the triangle involved in the purchase and use of green products, each one has faced a number of challenges. Although the role of governments and companies in protecting the environment is important and undeniable, consumers have a much more important role to play in protecting the environment; in fact, consumers can help protecting the environment by purchasing and using green products.

Fortunately, evidences suggest that consumer concern in Iran has also increased in relation to environmental issues and green market segmentation have emerged among consumers. However, unfortunately little researches have been made on the attitudes of Iranian consumers towards green products in which only the negativity, positivity, or neutrality of attitudes have been measured. While researchers believe that consumers attitudes are changing by the change of factors affected on their attitudes about green products, this means changing consumer attitudes and, consequently, unwillingness to buy green products by them. Because of the importance of sources of attitudes toward green products, researchers such as Haghighi and Khalil (2011)

Understanding the factors influencing consumers' green purchasing behavior may help eliminate barriers of green consumption. Previous studies related to the willingness and customers' green purchasing behavior have often been made in developing countries and have shown their attitude towards buying green products (Han and Kim, 2010).

The present researches use planned behavior theory (TBP) which is a framework for understanding consumers' behavior towards purchasing green products. (TBP) is considered as one of the useful frameworks for explaining human behavior in a wide range of fields, and in particular its great efficiency in environmental psychology (Beaman, 2008). While in the case of Iran, which is a developing country, there are few studies that focus on consumers' behavior towards purchasing green products. This study is one of the initial attempts to understand the consumer purchasing behavior that comes from (TBP) framework (including belief structures) in Iran. In this regard, the present study seeks to answer these questions: What factors affecting purchase attitude and intention of consumers to buy green products in developing countries such as Iran?

\section{Theoretical Fundamentals and Research Background}

The need to produce ecological products and green business activities has forced companies to integrate environmental issues with marketing efforts and strategies, (Moein nejad, 2011). Unfortunately, most people believe that green marketing refers exclusively to promoting or advertizing products with environmental characteristics. Words such as non-phosphorous, recyclable, and ozone-friendly are cases that often consumers believe that they associate with green marketing, while these words are just signs of green marketing. Generally, green marketing has wide range of concept that can be applied to consuming, services, and industrial goods. Green marketing refers to the development of pricing improvement, promotion, and distribution of products that are less harmful to the environment (Saemian 
and Zare poor, 2010). According to the definition of (Berin, S. \& Kerf, L. and Keishnan, G, (2011)), a green product is a product that has the following criteria: Designing in a way that can be used, assembled and re-produced, and also materials used in its production that can be recycled. Having efficiency in terms of energy consumption and causing environmental pollution lower than other products (Ranaei Kurdsholi and Yari Bozjani, 2011, 168), and in general terms, it can be defined as a product that produces less environmental damages (Mahnes, 2008). Among the studies conducted in the field of green marketing, Nakhaei(2014) study showed that there is a positive and significant relationship between each of the mixed elements of green marketing and the consumer purchasing decision-making process. The results of Mohammadian's study (2017) showed that the four factors of social impact, environmental concerns, understanding of people from social responsibility and people's concern about personal perception have the most impact in young people's buying.

\section{Attitude}

Attitude can be defined as a positive / negative evaluation of a person from specific behavioral performance. Willingness and are the results of behavioral beliefs (BB) and outcome evaluation (OE). Behavioral belief refers to personal beliefs about the results of a particular behavior, while the outcome evaluation is the consistency of desirable or undesirable judgment about probable outcomes of behavior (Biker et al., 2014).In 1969, after various studies, Wicker concluded that despite what seemed there was a close relation between attitude and behavior, the attitude may not be closely related to behaviors or only slightly related to obvious behaviors (Ajzen, 2008). The results from the findings of Ramezanian (2013), Mojoodi(2012), and Chen and Chang (2014) showed that the attitude of people's efforts to control the perception of others is a process characteristics by which the person can understand others what his personality or specificity is and as a result, this attitude by transferring to others about green products, can increase their willingness to buy green products.

\section{Subjective Norms}

The subjective norm is defined as the pressure on one person to participate in a particular behavior. Subjective norms are beliefs for a social agent in nature. Subjective norms are a result of the normative beliefs (NB) and the compliance motivation (MC). The compliance of normative beliefs refers to individual's contribution about how others (those who are important) love to behave in a particular position, while the compliance motivation refers to the desire of individuals to match with the opinions of the most important people. The results of the research by Robinson \& Bennett (2013) and Schwartz (2005) showed that subjective norms are in fact the internal emotional sense that forces an individual to act ethically and motives those behaviors that are consistent with his values, and these norms help predict environmentally conscious behavior and thus affect the consumer's desire to buy green products.

\section{Perceived Behavioral Control}

Controlling perceived behavior means the ease or difficulty of an individual's understand of doing particular behavior. Perceived behavioral control is a result of control beliefs (CB) and perceived power (PP). Control beliefs can be defined as beliefs of individuals about the presence of specific factors that may facilitate or impede the performance of a particular behavior (eg, time, money, and opportunity), while perceived power refers to the personal evaluation of the influence of these factors in facilitating or preventing particular behavior (Ayzen, 2006). Perceived behavioral control refers to one's perception of the quality of doing a behavior (Easy or difficult)(Bandura, 2006). Considering perceived behavioral control in 
addition of behavioral intention is also useful. Whatever perceived behavioral control seems to be real; it can serve as a representative for real control and also predicting the desired behavior (Olson, 2003).

\section{Behavioral Intention}

Behavioral intention is the readiness of individuals to perform a behavior. It is supposed that there is an evident record of behavior. A greater tendency toward behavior, and more subjective norms, and more perceived behavioral control can increase an individual intention to conduct behavior (Notani, 2008). In terms of the intention of young consumers to buy green products, some scholars highlighted the high values of young consumers and suggested that social awareness cannot lead to their caring behavior (Mesrolian, 2016). (Akehurst, 2015) showed in a study that environmentally conscious behavior of consumer and the intention of green purchase by the consumer can cause green purchase behavior in consumer. The results of the research carried out by Zandhesami and Parvinchi (2014) and Dehnavi (2015) show that intention is a sign of a person's readiness for doing a particular behavior which comes precisely before the behavior. The intention based on the individual's view of behavior, is an objective norm and perceived behavioral control, which each factor is valued based on its relationship with the behavior and the beneficiaries. On the other hand, the Bowie-Chen studies in 2016 in Malaysia by raising the question that whether there is an environmental concern or not, have reached to this conclusion that concern does not play a meaningful role in environmental behavior.

\section{Perceived Value}

Zeitmal (1988) defined perceptual value as a general assessment of the product desirability, based on understanding what was received and what was given. The buyer perception of value shows the relationship between the quality or the benefits received from the product, and the values lost in perceiving the price of the product (Dades et al., 2001). Value is an emotional constraint created between a customer and producer after the customer consumes the product or service that the supplier produces (Goodsetin and Batez, 2006). The results of Dehnavi's research (2015) show that the effect of the variables of conscious behavior, perceived value, and the perceived effectiveness of the consumer on the intention of green purchase is significant, and also perceived risk, and environmental concern are the variables whose effects on intention of green purchase about an explained example have not been confirmed.

\section{Willingness to pay surplus}

The concept of willingness to pay refers to the total paid fee which indicates the difference between the consumer surplus welfare before or after adding or improving one of the characteristics of consumer's goods (Rosen, 2005). In a study, Dipitro (2013) concluded that among environmental factors, environmental saving has the most impact on the intention of green purchase. Goldberg \& Rosen (2010), Jang, Kim \& Lee (2016) and Leah \& Hatcher (2012) have shown that many consumers are looking for environmental safety and are willing to pay more for green products since it increases the level of desirability and will lead to the reduction of health risks simultaneously. 

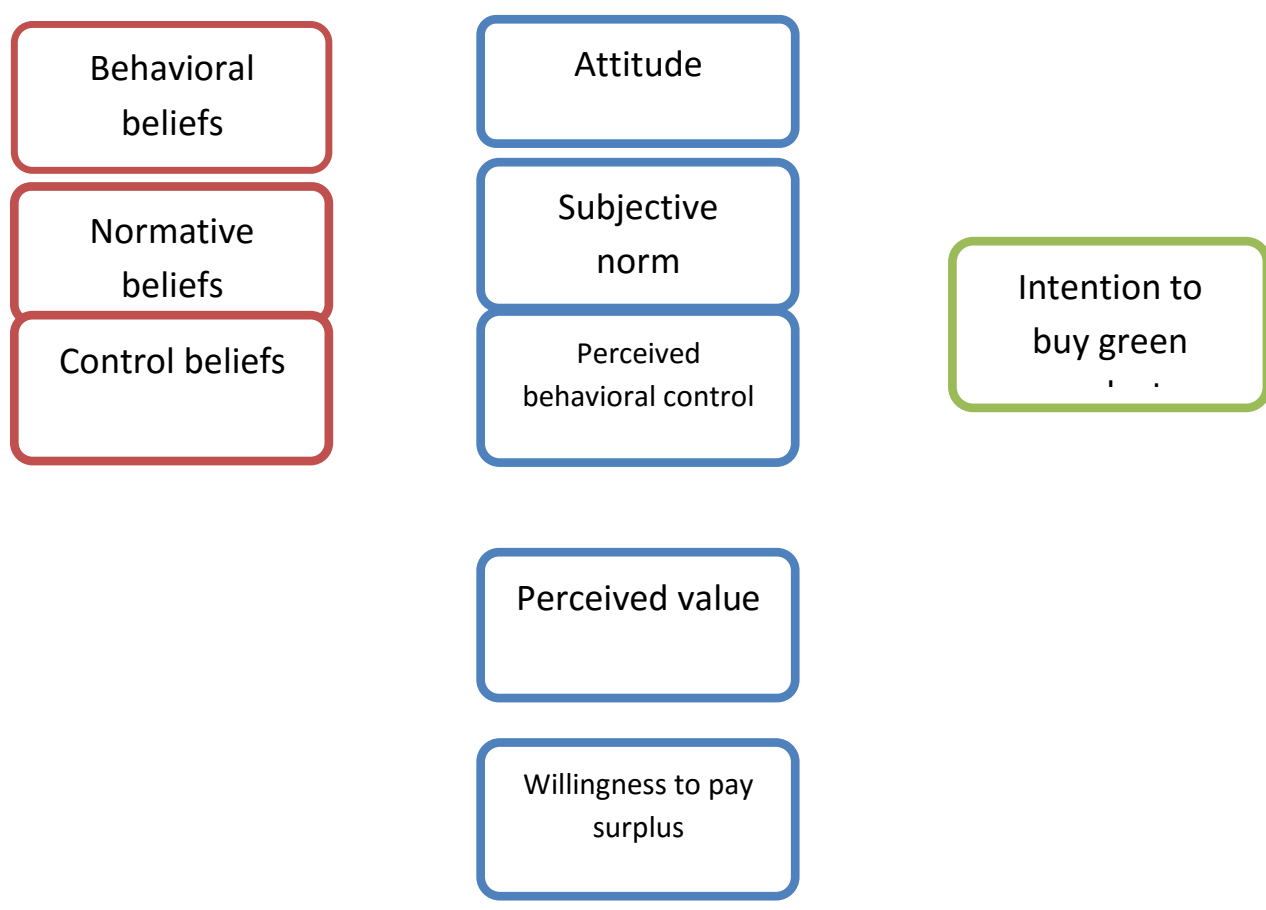

Figure 1: Conceptual model (derived from Yadav and Patke Model, 2017)

\section{Research Method}

This is an applied research in terms of its goal and considered as descriptive- co relationalsurvey research. Collecting information is done through library and field methods. The statistical population of this research is all customers of large stores (hyperme and hyperstar) in Tehran who have green products in their shopping basket. In this research, to collect required information, after determining the sample size using unlimited Cochran formula, 384 questionnaires were distributed and then Kolmogorov-Smirnov test was used to determine the normality of data and content validation method was used to evaluate the validity of the questionnaire. The calculated Cronbach's alpha coefficient in this study in a preliminary study by distributing 20 questionnaires was 0/95.4. Therefore, the reliability of the questionnaire is highly desirable. The research variables were behavioral beliefs, normative beliefs, control beliefs, attitudes, subjective norm, perceived behavior control, perceived value, willingness to pay value added, intention to buy green products, purchase behavior. Standard questionnaires were used to evaluate each of the variables. To analyze the data, descriptive tests such as percentage, mean and standard deviation and inferential tests such as Pearson correlation, confirmatory factor analysis and structural equations with LISREL Software were used.

\section{Results}

In order to analyze the statistical data of the present study, firstly, the information obtained from existing documents about the company has been examined. Also, since the researcher used a questionnaire to collect other information, for analyzing the data of this section, the data were first extracted from the questionnaires and placed in the general information table or the mother table. Then, all data and information was analyzed using SPSS software and computer software in descriptive and inferential methods.

\section{Demographic Research Studies}

By examining the demographic axis, from 384 samples, 200 were male and 184 were women; 10 were less than diploma students; 54 had diplomas; 115 were associate degree students; 
174 were bachelor's degree students; and 31 were master's degree students or more level; in terms of the age, 13 were $18-25,85$ were $26-35,148$ were $36-45 ; 138$ were over 56 years old.

\section{Confirmatory Factor Analysis}

Confirmatory factor analysis considers the relationship between the items (questionnaire questions) and the structures. In fact, the research hypotheses cannot be used based on the questionnaire data until it is proven that questionnaire questions have well measured the hidden variables. Therefore, a confirmatory factor analysis is used to prove that the data are accurately measured. Six major factors (hidden variables) and 31 questions (visible variables) were used to measure the structural model of the research. Each of these variables is represented by the index Q_01 to Q_31 in the following table.

Table 1: Results of confirmatory factor analysis

\begin{tabular}{|c|c|c|c|}
\hline & Items & Standard factor loading & T statistic \\
\hline \multirow{10}{*}{ Behavioral beliefs } & Q01 & 0.43 & 3.68 \\
\hline & Q02 & 0.57 & 7.06 \\
\hline & Q03 & 0.61 & 5.88 \\
\hline & Q04 & 0.38 & 2.07 \\
\hline & Q05 & 0.43 & 4.5 \\
\hline & Q06 & 0.32 & 2.34 \\
\hline & Q07 & 0.31 & 2.39 \\
\hline & Q08 & 0.33 & 2.08 \\
\hline & Q09 & 0.39 & 2.26 \\
\hline & Q10 & 0.34 & 2.59 \\
\hline \multirow{6}{*}{ Normative beliefs } & Q11 & 0.33 & 2.21 \\
\hline & Q12 & 0.36 & 2.20 \\
\hline & Q13 & 0.35 & 2.21 \\
\hline & Q14 & 0.75 & 2.19 \\
\hline & Q15 & 0.33 & 2.97 \\
\hline & Q16 & 0.33 & 2.12 \\
\hline \multirow{6}{*}{ Control beliefs } & Q17 & 0.37 & 2.78 \\
\hline & Q18 & 0.58 & 5.01 \\
\hline & Q19 & 0.43 & 3.27 \\
\hline & Q20 & 0.30 & 2.50 \\
\hline & Q21 & 0.32 & 10.66 \\
\hline & Q22 & 0.34 & 2.38 \\
\hline \multirow{6}{*}{ Attitude } & Q23 & 0.37 & 4.50 \\
\hline & Q24 & 0.30 & 6.88 \\
\hline & Q25 & 0.34 & 3.19 \\
\hline & Q26 & 0.32 & 3.56 \\
\hline & Q27 & 0.38 & 4.23 \\
\hline & Q28 & 0.33 & 2.19 \\
\hline \multirow{2}{*}{ Subjective norm } & Q29 & 0.36 & 2.44 \\
\hline & Q30 & 0.33 & 5.15 \\
\hline \multirow{3}{*}{$\begin{array}{c}\text { Perceived } \\
\text { behavioral control }\end{array}$} & Q31 & 0.35 & 3.45 \\
\hline & Q32 & 0.38 & 3.31 \\
\hline & Q33 & 0.83 & 3.12 \\
\hline \multirow{2}{*}{ Perceived value } & Q34 & 0.33 & 4.11 \\
\hline & Q35 & 0.96 & 7.27 \\
\hline
\end{tabular}




\begin{tabular}{|c|c|c|c|}
\hline & Items & Standard factor loading & T statistic \\
\hline & Q36 & 0.51 & 5.25 \\
\hline & Q37 & 0.52 & 3.25 \\
\hline & Q38 & 0.38 & 3.33 \\
\hline \multirow{2}{*}{$\begin{array}{l}\text { Willingness to pay } \\
\text { value added }\end{array}$} & Q39 & 0.41 & 2.30 \\
\hline & Q40 & 0.36 & 3.41 \\
\hline \multirow{3}{*}{$\begin{array}{c}\text { Intention to } \\
\text { purchase green } \\
\text { products }\end{array}$} & Q41 & 0.41 & 3.20 \\
\hline & Q42 & 0.66 & 6.05 \\
\hline & Q43 & 0.72 & 7.05 \\
\hline \multirow{3}{*}{ Purchase behavior } & Q44 & 0.41 & 3.25 \\
\hline & Q45 & 0.38 & 6.00 \\
\hline & Q46 & 0.38 & 7.05 \\
\hline
\end{tabular}

The factor loading in all cases is greater than 0.3 , which indicates that the correlation between hidden variables (dimensions of each of the main structures) and visible variables is acceptable. After identifying the correlation of variables, a meaningful test should be performed. The t-value statistic is used to determine the significance of the relationship between variables. Since significance is checked at the error level of 0.05 , so if the t-value test statistic is greater than the critical value of 1.96, then the relationship is significant. Based on the results of the measurement indices of each of the scales used at the 5\% confidence level, the value of the t-value statistic is greater than 1.96, which indicates that the observed correlations are significant.

The RMSEA index is used in most of the confirmatory factor analysis and structural equations models as a major fit index. If this index is smaller than 0.05 , it is desirable. In the saturated model of this research, the RMSEA index is equal to 0.039 , which indicates that the model fit is desirable. 


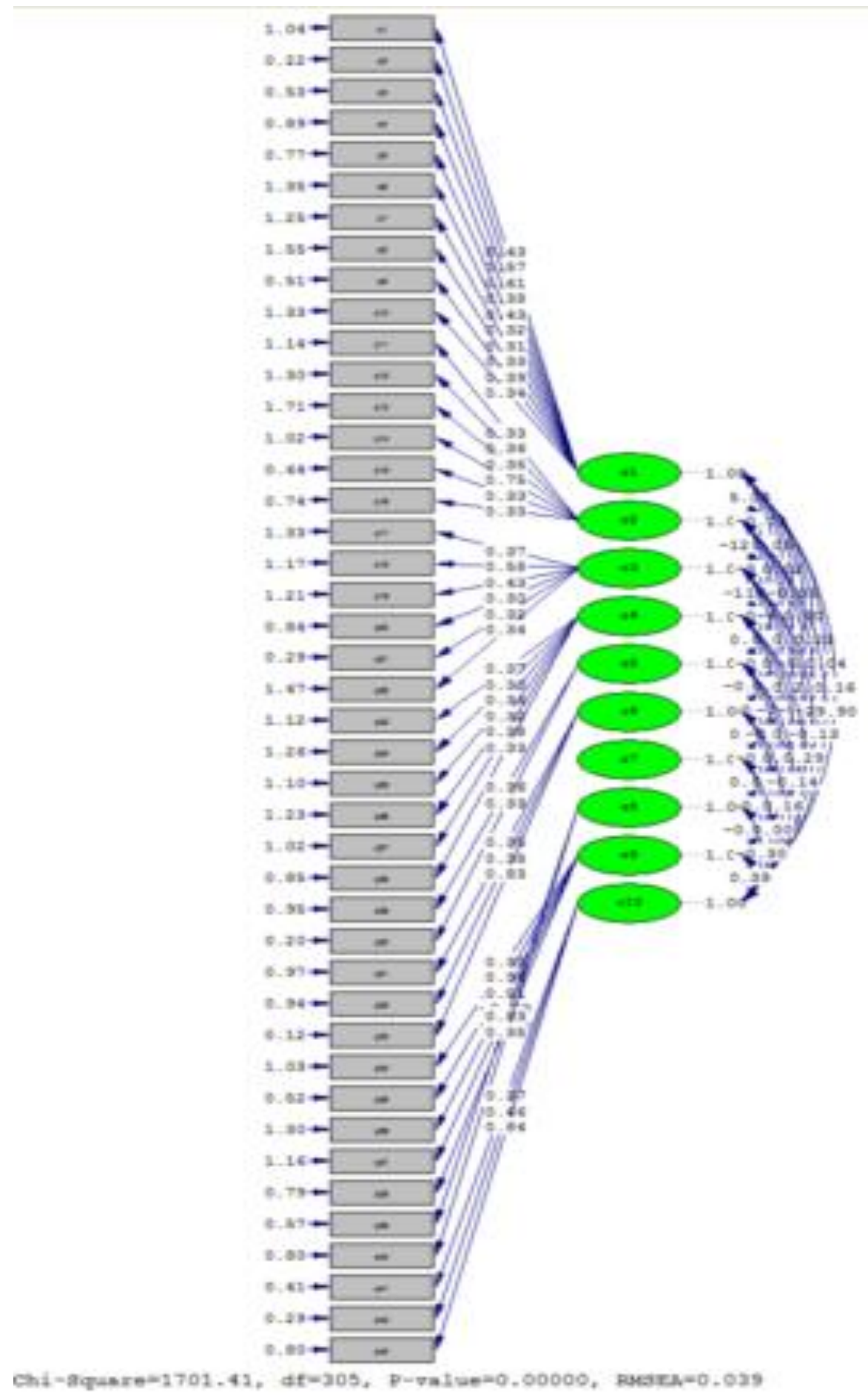

Figure 2: Standard factor loading of confirmatory factor analysis of research scale 


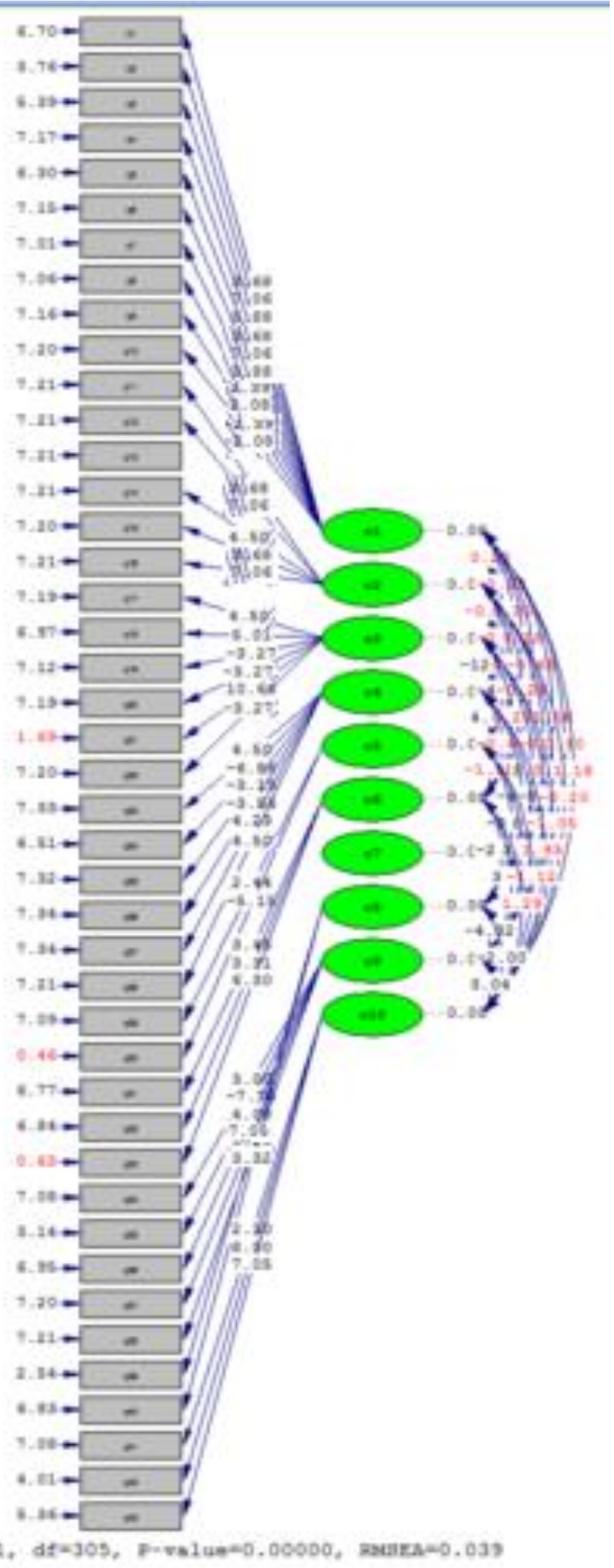

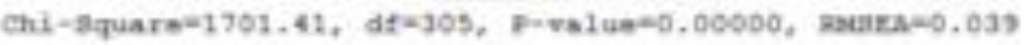

Figure 3: t statistic value (significance) of confirmatory factor analysis of research scale 


\section{Test of research hypotheses}

After verifying the factor structure of the research structures, structural equation modeling has been used to study the relationships between the variables. In this model, the relationships between research variables can be observed in the output of the LISREL software.

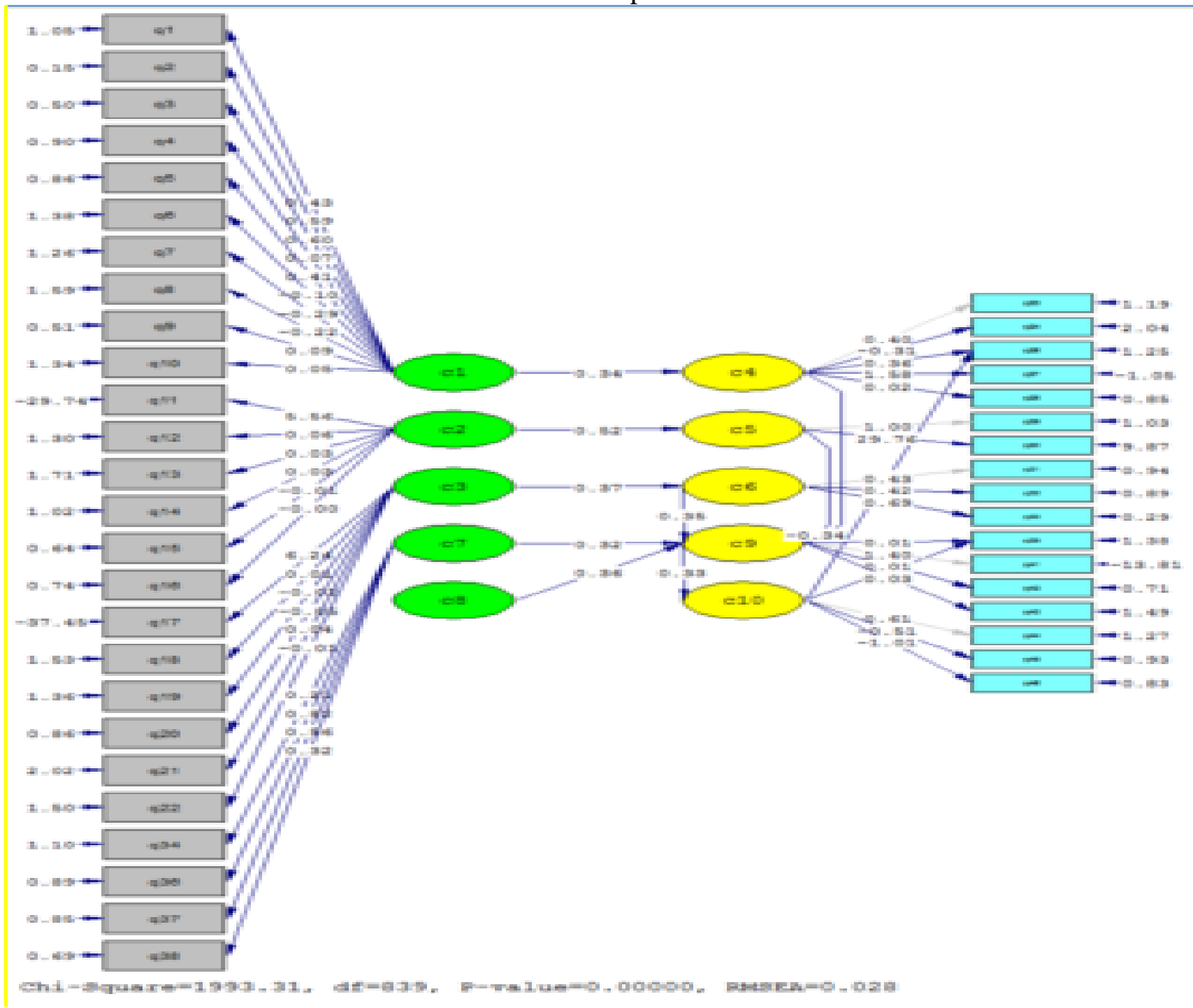

Figure 4: Standard factor loading of hypotheses research test (main hypothesis) 


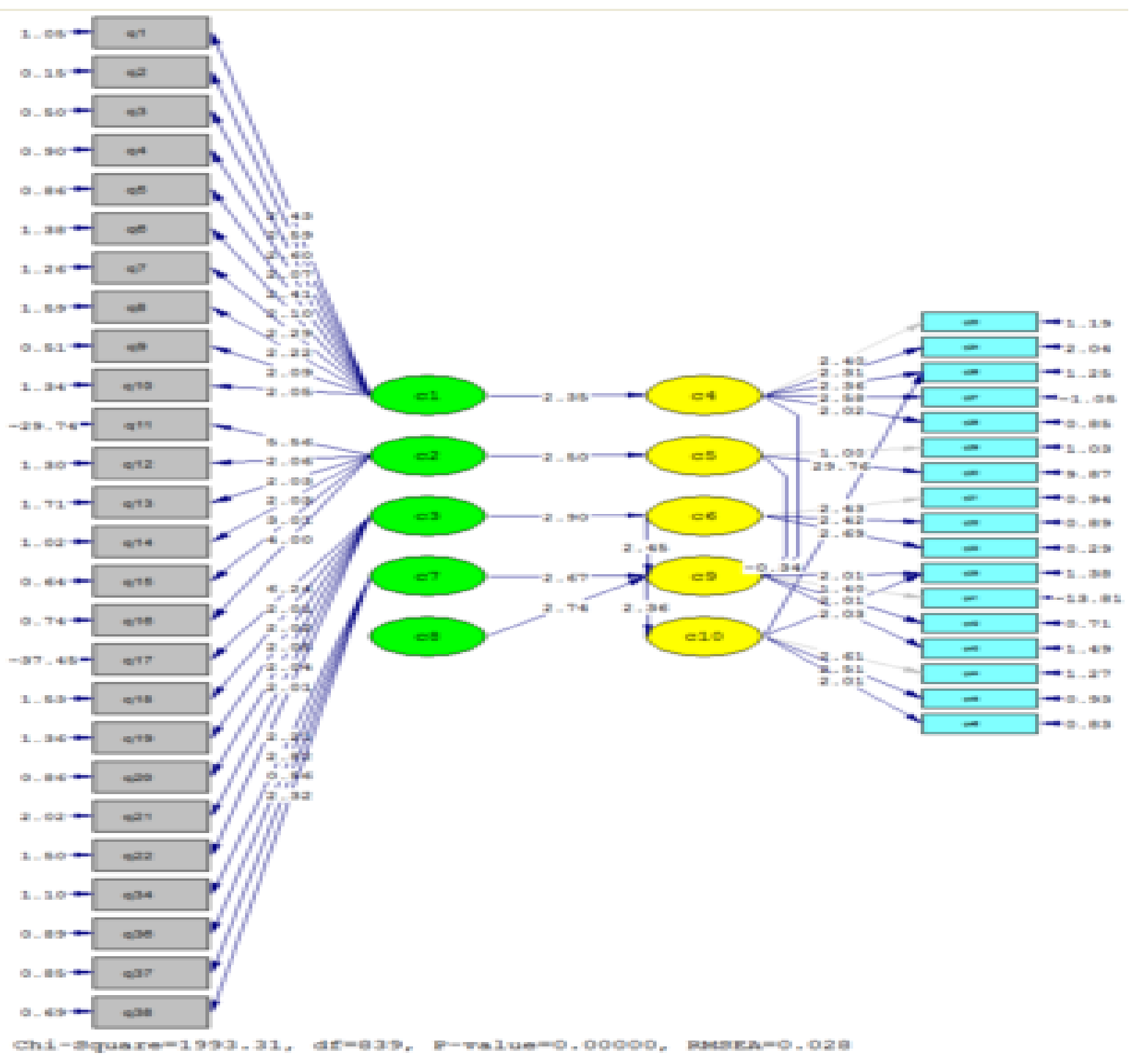

Figure 5: T value static of research hypotheses test

\section{Hypotheses}

1. Hypothesis (one): Behavioral beliefs affect significantly on the attitude toward green products.

The relationship power between the behavioral beliefs variable and the attitude toward green products variable has been estimated to $0 / 34$, which is considered as an acceptable value. The test statistic is also 2.35, which is greater than the t critical value at the error level of $5 \%$, ie, 1.96 which indicates that the observed correlation is significant. Therefore, behavioral beliefs affect significantly on the attitude toward green products.

2. Hypothesis (two): Normative beliefs affect significantly on consumers' subjective norms. The relationship power between the normative beliefs variable and the consumer's subjective norms variable has been estimated to 0.52 , which is an acceptable value. The test statistic is also 2.50, which is greater than the $t$ critical value at the error level of 5\%, ie, 1.96 which indicates that the observed correlation is significant. Therefore, normative beliefs affect on the subjective norms of consumers.

3. Hypothesis (Three): Control beliefs affect significantly on the perceived behavioral control. 
The relationship power between the control beliefs variable and the perceived behavioral control variable has been estimated to $0 / 37$, which is considered as an acceptable value. The test statistic is also 2.90, which is greater than the t critical value at the error level of $5 \%$, ie, 1.96 , indicating that the correlation is significant. Consequently, control beliefs affect on perceived behavioral control.

4. Hypothesis (Four): Attitudes affect significantly on the consumer's intention to purchase green products.

The relationship power between the attitude variable and the consumer's intention to purchase green products variable has been estimated to 0.32 , which is considered as an acceptable value. The test statistic is 2.67 , which is greater than the $t$ critical value at the error level of $5 \%$, ie, 1.96, indicating that the observed correlation is significant. Therefore, the attitude affects on consumers' intention to purchase green products.

5. Hypothesis (Five): Subjective norms significantly affect on consumers' intention to purchase green products.

The relationship power between the variable of subjective norms and the consumer's intention to purchase green products variable has been estimated to 0.36 , which is considered as an acceptable value. The test statistic was 2.74 , which is larger than the $t$ critical value at the error level of 5\%, ie, 1.96, indicating that the correlation is meaningful. Subjective norms, therefore, affect on the consumer's intention to purchase green products.

6. Hypothesis (Six): Perceived behavioral control affects significantly on the customer's intention to purchase green products.

The relationship power between the variable of perceived behavioral control and the consumer's intention to purchase green products variable has been estimated to 0.35 , which is considered as an acceptable value. The test statistic is also 2.45 which is larger than the $t$ critical value at the error level of $5 \%$, ie, 1.96, indicating that the observed correlation is significant. Therefore, the use of perceived behavioral control affects on consumers' intention to purchase green products.

7. Hypothesis (Seven): Perceived value affects significantly on the customer's intention to purchase green products.

The relationship power between the variable of perceived value and the consumer's intention to purchase green products variable has been estimated to 0.33 , which is considered as an acceptable value. The test statistic is also 2.34 which is larger than the $t$ critical value at the error level of 5\%, ie, 1.96, indicating that the observed correlation is significant. Therefore, the use of perceived value affects on consumers' intention to purchase green products.

8. Hypothesis (Eight): The willingness to pay surplus (above nominal value) affects significantly on the customer's intention to purchase green products.

The relationship power between the variable of willingness to pay surplus and the consumer's intention to purchase green products variable has been estimated to 0.34 , which is considered as an acceptable value. The test statistic is also 2.36 which is larger than the $t$ critical value at the error level of $5 \%$, ie, 1.96, indicating that the observed correlation is significant. Therefore, the use of willingness to pay surplus affects on consumers' intention to purchase green products.

9. Hypothesis (Nine): The intention to purchase green products affects significantly on the customer's purchase behavior. The relationship power between the variable of the intention to purchase green products and the consumer's purchase behavior variable has been estimated to 0.34 , which is considered as an acceptable value. The test statistic is also 2.42 which is larger than the $t$ critical value at the error level of $5 \%$, ie, 1.96, indicating that the observed correlation is significant. Therefore, the use of the intention to purchase green products affects on consumers' purchase behavior. 
Goodness of model fit

The above structural model is saturated in three stages. Fit indices show good values. The normal value of Chi-squared is also $1 / 459$, which is within the accepted range of 1 to 5 . Therefore, the structural model has a desirable fit.

$$
\frac{\chi^{2}}{\mathrm{df}}=\frac{354.57}{243}=1.459
$$

Also, since the fit index of RMSEA is 0.079 , which is less than 0.05 , the model has a good fit. Other indices of fit goodness also have been within acceptable range.

\section{Discussion and Conclusion}

The purpose of this study was to answer the question of which factors affect the attitude and intention of consumers to purchase green products in developing countries such as Iran? According to the results, behavioral, normative and control beliefs affect individuals' attitude toward purchasing green products, as well as attitude, subjective norms, perceived behavioral control, and perceived value also affect consumers' intention to purchase green products. In the first hypothesis, we showed that behavioral beliefs affect individuals' attitude toward green products. The obtained results are consistent with the results of Hosseini (2015) and Dehnavi (2015). The reason for this is that consumers' environmental concerns have led them to change their purchasing behavior gradually and consider again the purchased products. In this regard, the more consumer behaves consciously, his intention to purchase green product will be increased too. Subjective norms are a reflection of social pressure perceived by a person and form a distinct behavior. In fact, subjective norms indicate how a customer is influenced by the behavior and speech of some of the most important people in his life (for example, people like family members, friends, colleagues, etc.), as a result, subjective norms in comparison with attitudes play an important role in predicting consumer's behavioral purposes, and these subjective norms can have an impact on individuals' attitudes towards green products, and if consumers believe that others have good attitude towards green products, their intention to purchase these products will be increased. The obtained results are in line with the results of studies conducted by Ritter, Borchardt, Vakrof Perira, and Almadia (2017), and Mojoodi(2012). In the third hypothesis, we examined the influence of control beliefs on the attitude toward green products. Control beliefs are associated with a number of perceived factors that may enhance or prevent the occurrence of a behavior. It is thought that these beliefs, in combination with the power of each control factor, determine the dominant perceived behavioral control, in particular, the power of each control factor plays role in the enhancement or prevention of a behavior in perceived behavioral control and directly connects with this objective probability that control factor exists externally. Perceived behavioral control indicates that an individual's motivation is influenced by one's understanding of the difficulty of behaviors and the extent to which he or she succeeds in doing or not doing a behavior. If a person has strong control beliefs over the existence of facilitators of a behavior, he or she will have a high perceived control over one behavior. Therefore, control beliefs about green products can affect their attitude towards purchasing these products. The results of this study are consistent with the findings of Akhurst (2015), Nakhaei (2014), and Ramezanian (2013).

In the fourth to ninth hypotheses, we discussed about the effect of subjective norms, perceived control, and perceived value, and a willingness to pay surplus on the attitude toward purchasing green products, and finally, we talked about the impact of the intention of purchasing green products on customers' behavior. Increasing people's awareness of 
environmental issues, which is the same perceived value, can lead to forming a new attitude, followed by purchasing behavior and ultimately the intention to purchase green products. On the other hand, today, due to the many concerns associated with the gradual destruction of the environment and the threat to the health of individuals and their survival, people are willing to pay a surplus to support green products to maintain the health of the environment they live in. Also, when the intention to purchase green products is increased, customers' behavior is also affected, and customers are trying to maintain environment and encourage others to do so. Therefore, we conclude that collectivist values affect consumer's perceptions towards their effectiveness on environment, and thus affect their green purchasing behavior. The obtained results are consistent with the findings of Ramezanian (2013), Mojoodi(2012), Zandhesami and Parvinchi (2014), Dehnavi (2015), Mohammadi and Rafi (2011), Chen and Chang (2014), Gary et al. (2012) ), Robinson \& Bennett (2013), Schwartz (2005), Deepitro (2013), Goldberg \& Rosen (2010), Jang, Kim \& Lee (2016) and Leah \& Hatcher (2012). According to the research hypotheses, it is suggested that legislators and authorities focus on preserving natural resources as the first priority and reducing the environmental consequences of non-environmentally friendly products as the second priority, to develop programs for creating behavioral beliefs in individuals. In addition, the most important protective behavior towards environment in terms of the green consumer is to dispose of waste properly.

Since the family has the first place in terms of effective social groups, green products manufacturers and marketers are trying to reinforce environmentally-friendly behaviors by the family and firstly target the family to promote their products. In addition, marketers can take action through the use of social pressures to increase everyone's green purchasing intention.

It is also suggested that marketers, by identifying the factors influencing green purchasing, can strive to strengthen and control their behavior, and lead the consumer more into green behavior, and also it is suggested that authorities by planning environmentally-friendly strategies as a way for green marketing, create a green attitude in people. Ultimately, the retailers are advised to inform their customers about the green activities they are doing or the green products they are providing.

Finally, since green consumer prefers environmentally friendly products and organic food products, it is recommended to conduct researches on magnitude of this trend and market potential estimation for organic products.

\section{References}

Dehnavi, Samaneh (2015), "The Role of Brand Personality on Consumer Behavior and Branding Challenges in Asia"

Haghighi, Ali Asghar, Khalil, Maryam (2011). "A comparative study on the quality of banking services from the perspective of customers and employees."

Hosseini, Atefeh (2016), "Investigating the Effect of Brand value from Employees' view on Brand value in Industrial Markets", Case Study of Industrial Town No. 1 in Dezful,

Moeinnejad, Habib (2011), "Evaluation of methods for assessing the quality of services by artificial neural networks", Business Management Perspective, Vol. 8, No. 31, pp. 63-79.

Mohammadian, Mehdi and Khatei, Masoud (2011), "The study of the relationship between the quality of Mellat's electronic services and customer loyalty by using structural equation modeling", Development Management (Special Letter), pp. 1-12

Mohammadian, Raheil (2017), "The determinants of the special value of sport shoes brand among young age group". Journal of Humanities and Social Management, Year 7 No. 25 
Mojoodi, p. (2012). "Explaining the Concept of Social Marketing", Quarterly Journal of Business Journal, No. 28, p. 141-163.

Mussender, Jacques (2007), "Seven Service Strategy Keys", translators: Seyed Mohammad Arabi and Davoud Izadi, Cultural Research Office. Nakhaei, Abolfazl; (1393), "The Relationship between Branding and Performance Indicators." Journal of Health Management, No. 13

Papalicamouno, Dell (2011); Consumer Behavior; Translators : Ahmad Rousta and Atieh Bahayi, Sargol Publications.

Ramezanian, Seyedeh Elham (2010), "Studying the Effect of Marketing Variables and Specific Brand value Dimensions on the Preference and Intent of Purchasing a Brand Name (Case Study: Major Commercial Names in Iran's Food Industry)"

Ramezanian, Seyedeh Elham (2013), "Studying Consumer Reaction to the Brand Extension Strategy (Trademark Generalization), A Case Study : Shirin Asal and Tak Macaron Companies"

Saemian, Seyed Reza Zarepour, Mahnaz (2010), "The value of trade mark in the banking industry". First International Conference on Banking Services Marketing, Tehran, 2-21 